\title{
A Review of Injectable and Implantable Biomaterials for Treatment and Repair of Soft Tissues in Wound Healing
}

\author{
Shih-Feng Chou, ${ }^{1}$ Simi Gunaseelan, ${ }^{2}$ Mhd Hussam Hijazi Kiellani, ${ }^{1}$ \\ Venkata Vamsi Krishna Thottempudi, ${ }^{1}$ Pierre Neuenschwander, ${ }^{3}$ and Huarong Nie ${ }^{4}$ \\ ${ }^{1}$ Department of Mechanical Engineering, College of Engineering, The University of Texas at Tyler, Tyler, TX 75799, USA \\ ${ }^{2}$ Department of Pharmaceutical Sciences, Ben and Maytee Fisch College of Pharmacy, The University of Texas at Tyler, \\ Tyler, TX 75799, USA \\ ${ }^{3}$ Department of Cellular and Molecular Biology, The University of Texas Health Science Center at Tyler, Tyler, TX 75708, USA \\ ${ }^{4}$ Key Laboratory of Rubber-Plastics, Ministry of Education, Qingdao University of Science and Technology, Qingdao 266042, China
}

Correspondence should be addressed to Shih-Feng Chou; schou@uttyler.edu

Received 9 February 2017; Accepted 23 April 2017; Published 5 June 2017

Academic Editor: Paresh Chandra Ray

Copyright (C) 2017 Shih-Feng Chou et al. This is an open access article distributed under the Creative Commons Attribution License, which permits unrestricted use, distribution, and reproduction in any medium, provided the original work is properly cited.

\begin{abstract}
The two major topics concerning the development of nanomedicine are drug delivery and tissue engineering. With the advance in nanotechnology, scientists and engineers now have the ability to fabricate functional drug carriers and/or biomaterials that deliver and release drugs locally as well as promote tissue regeneration. In this short review, we address the use of nanotechnology in the fabrication of biomaterials (i.e., nanoparticles and nanofibers) and their therapeutic function in wound healing as dressing materials. Furthermore, we discuss the use of surface nanofeatures to regulate cell adhesion, migration, proliferation, and differentiation, which is a crucial step in wound healing associated with tissue regeneration. Given that nanotechnology-based biomaterials exhibit superior pharmaceutical performance as compared to the traditional medicine, this short review provides current status and future directions of how nanotechnology is and will be used in biomedical field, especially in wound healing.
\end{abstract}

\section{Introduction}

Recent development in nanotechnology facilitates the advance of biomaterials in their structure-property-function relationships. Functional biomaterials have outstanding pharmaceutical performance in drug delivery and tissue engineering. For example, nanoparticles have been used for drug delivery vehicles in many disease states. These onedimensional biomaterials are often made from natural or synthetic polymers that are biodegradable so that the encapsulated drug can be programmed for a particular release rate. Another form of drug carriers utilizing nanotechnology is electrospun naonofibers. Fibers are considered as twodimensional biomaterials where the high surface area and the porous structure provide excellent therapeutic efficacy in drug release. These nanotechnology-based biomaterials have the potential in promoting cell interaction with the drug carrier and therefore making them ideal candidates in drug delivery applications.
In parallel to drug delivery, nanotechnology-based biomaterials are often used in stimulating cellular responses either by the released agents or by the surface texture alone. In the latter case, research typically addresses cell cultivation to preserve its gene expression so that its differentiation can be maintained for tissue regeneration purpose. Surface features and/or surface properties of a biomaterial (e.g., films or substrates) have a significant influence on cell adhesion, migration, proliferation, and differentiation. Having the ability of using nanotechnology to control the surface features and/or properties is an important topic in the field of tissue engineering.

In this short review, we discuss nanotechnology-based biomaterials in the form of nanoparticles, nanofibers, and surface nanofeatures on the impact of wound healing. Aspects of drug delivery from nanoparticles and nanofibers are mentioned with the additional discussion of tissue regeneration using surface features. This brief review provides insights in current status of nanotechnology in the fabrication 
of biomaterials, how these functional materials promotes wound healing, and future directions of using nanotechnology in fabrication of biomaterials to achieve desire therapeutic functions.

\section{Nanotechnology-Based Biomaterials}

Nanotechnology, which is the manipulation of matter at the nanoscale related to atoms and molecules, has been used in many areas related to medicine, engineering, and electronics [1,2]. The importance of the relationship between nanotechnology and biomaterial comes out of three factors: biomaterial, nanotopography, and the relationship between the nanotechnology and the health care.

"Biomaterial" term has been designed for the human body in nanodimensions. Nanomaterials originally come from natural polysaccharides including many nanostructures such as nanoparticles, nanofibers, nanopin, nanosheet, nanobrush, and nanoclusters [3]. It has been proved that nanofibers materials have a superior motivation than other materials due to the huge surface area to the volume ratio [4].

Although these nanomaterials have been derived from bulk materials, they have different properties [5] such as pore morphology, porosity, and grain size [6].

The nanoparticle's size should not exceed $200 \mathrm{~nm}$ (i.e., the width of microcapillaries) since the human tissue is limited for large particles [7]. Depending on the way of preparation, a drug is mixed, absorbed, and/or attached into a nanomatrix by using different nanodevices [8]. These nanoparticles have advantages over the regular particles for drug delivery because of continued lifetime, the enhanced solubility, and the controlled rate of delivery [9]. Many scientists did many researches by using these features to develop the nanoparticles for drug releasing and tissue engineering [10].

Nanofibers can be processed by using different techniques like template synthesis, phase separation, electrospinning, and so forth [4]. However, the electrospinning process, which is a significant way to get a nanofiber material from all kinds of polymers [11], is the most suitable method to fabricate nanofibers. When nanofibers are formed by using elecrospinning, the surface area of fiber mesh is increased enormously. There are two methods to form porous nanofibers: the first one is when using more volatile compounds and the other one is when two different polymers are spun together [12]. Electrospun nanofibers are quite versatile and have many properties including the electron transportation, high density and thermal diffusivity, low cost, better control over fiber dimensions and structure, and high production rate and flexibility. Also, the fiber patterns and assemblies can be easily modified and controlled. In electrospinning, a repulsive force is created by applying a high voltage instead of extrusion force which is usually created by using air or mechanical devices $[4,12-14]$.

The importance of the biomaterial and nanotechnology should match not only the nanomaterial and its mechanical properties but also its topography. Actually, surface topography and fibers have many applications including fuel cells, absorption, and solar cells batteries [11]. But the most important, as recent studies show, are those that deal with the biomaterial or/and biomedical devices and their applications such as cellular engineering and tissue repairing [15]. Actually, it had been mentioned in previous researches that surface topography has a significant impact on the cell proliferation, adhesion, and differentiation [16]. A general way to control the cell reactions is the first step towards surface topography ranges in the micrometric or in the nanometric scale [17]. Recent studies show that these reactions happen more in the nanometric scale and have the importance of tissue engineering in general [18]. This finding introduces us to the "Nano/ Microtopography" term, which is the behavior of the cells having interactions with the biomaterial surfaces. The surface area of the fibers could be increased by the absorptive structure by removing a component from the fibers or using the phase separation $[19,20]$. For example, nanotopography provides more conclusive and porous sites for drug loading [11]. There are two categories of nanotopographies, which can be applied on materials. The first category is the unordered nanotopographies that occur during the process randomly (e.g., chemical etching and polymer demixing). The unordered nanotopographies are characterized by the low cost and simple use. The second category is the ordered topographies, which can be applied by using different techniques such as electron beam lithography and photolithography [21].

It has been recognized in recent years that the medical care depends essentially on treatment efficacy. However, finding the right cure before the disease appeared may be the future of the medicine [12]. The ability to predict diseases and identify the location of the potential diseased tissue highlights the importance of the relationship between nanotechnology and the healthcare. Nanotechnology has been influencing the quality of life through the development invention of new technologies $[22,23]$. By combining these factors with electrospinning, new medical care forms and patients will be present with a new and a more cost-effective choice for treatment. For example, nanofibers with different modules had been produced by electrospinning from synthetic and natural polymers with different dimensions in nanometer [14]. These fibers have the applications in tissue engineering, repairing, regeneration, drug delivery, healing treatments, cosmetics, and so forth $[12,13]$. One of the future researches is the fabrication of electrospun nanofiber of the blood vessels, nerves, bone, and skin [13].

\section{Current Status of Nanotechnology-Based Biomaterials in Soft Tissue Repair and Regeneration}

The two major functions of biomaterials are to carry small molecule drugs or large biological agents for local delivery and to stimulate, replace, and regenerate the lost function of tissue. With a wide variety of biomaterials being developed every year due to the improvement of nanotechnology, they all require meeting the criteria of biocompatibility to local tissue or cells. While metals and ceramics are widely used in engineering biomaterials, polymers have drawn many attentions in the application of biomaterials for a disease state owning to the advance in nanotechnology-assisted 


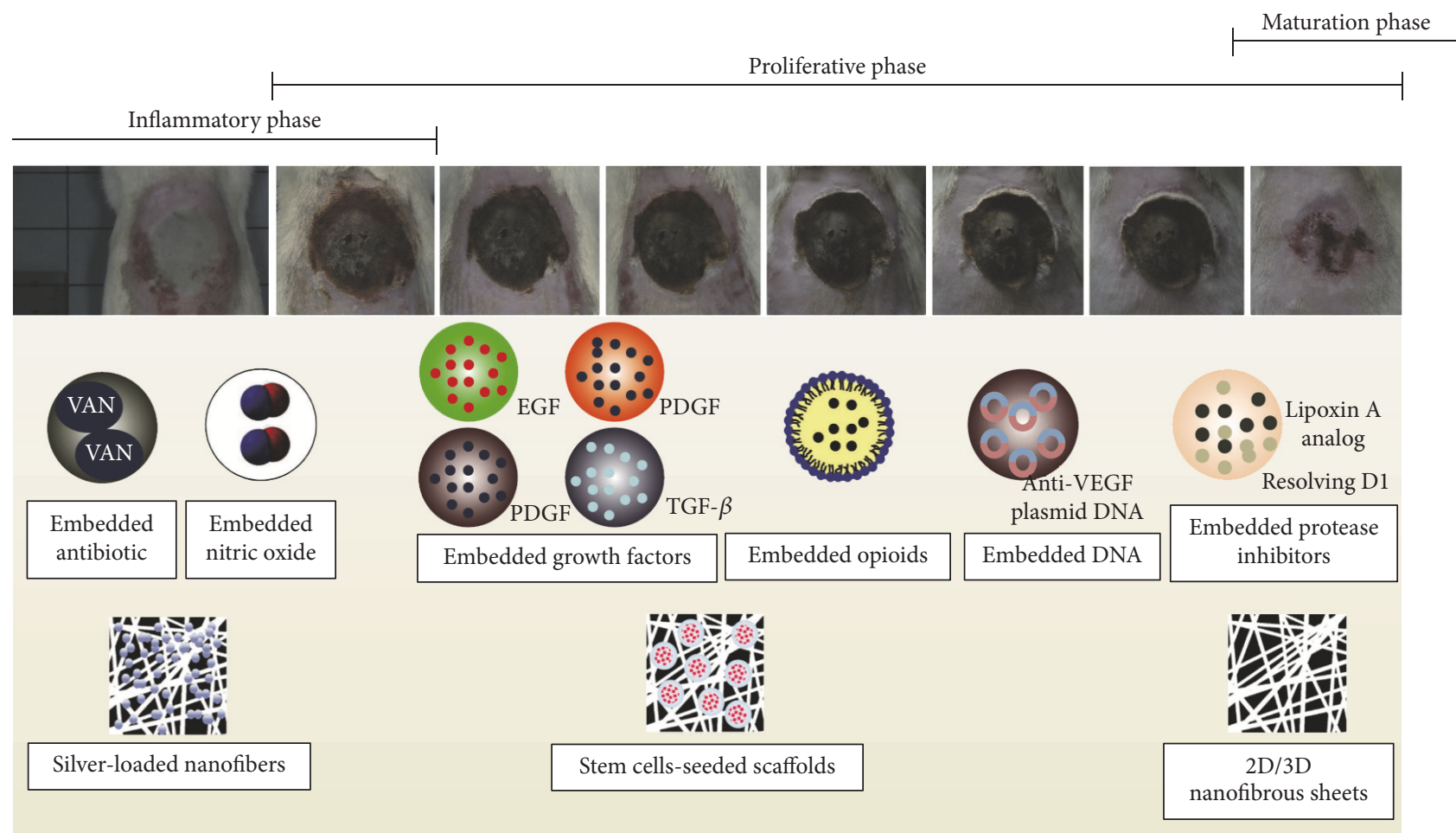

FIGURE 1: Schematics of current available nanotechnology-based dressing (e.g., nanoparticles and nanofibers) using in different stages of wound healing from an animal model [24, 25] (figure obtained from an open access article distributed under the Creative Commons Attribution License).

manufacturing methods. Nowadays, polymer-based biomaterials are being heavily studied for their structure-propertyfunction correlations in order to provide information on their applications. Given that polymers provide sufficient strength to soft tissues, they can serve as a structural support or a guided template for cell and tissue to grow. Another important advantage in using polymers as the base materials for a biomaterial is that it provides a degradation profile that can limit the extra surgical procedures to remove the biomaterial as an implant after tissue regeneration. The space available after polymer degradation allows cells and tissue to fill in. In addition, degradation of polymers plays a crucial role in temporal control of drug release when serving as a drug carrier. Since degradation of the polymer-based biomaterials dictates the function of themselves, the toxicity of the by-products and responses to host tissue remain a necessary topic for the application of nanotechnology-based biomaterials. Therefore, recent studies typically focus on the development of fully resorbable biomaterials. These resorbable materials are particularly useful to provide a temporary physical structure that stimulate and encourage tissue restoration and promote cell adhesion, migration, proliferation, and differentiation. Others focus on delivery of drugs and other molecules using the same principle.

The fabrication and design of degradable/resorbable are relatively easy using current available nanotechnologies. The difficulty for a particular biomaterial is how to meet the required treatment efficacy at levels and severity of the disease states under the restrictions of nearly the same intrinsic polymer degradation rate. In the following sections, as shown in Figure 1 [24, 25], we use different types of nanotechnologybased biomaterials, namely, nanoparticles/micelles/lipids, nanofibers, and nanofeatures from substrate materials to show the effectiveness of these biomaterials as dressings in chronicle and/or nonhealing wounds.

3.1. Nanoparticles/Micelles/Lipids. A variety of nanoparticlebased biomaterials such as metal nanoparticles, polymeric nanoparticles, silica nanoparticles, solid lipid nanoparticles, nanostructured lipid carriers, nanoemulsions, nanocapsules, micelles, liposomes, and nanosuspensions are being developed for controlled drug release aimed at wound healing applications. Due to their specific characteristics, nanoparticles such as nanocapsules, polymersomes, solid lipid nanoparticles, and polymeric nanocomplexes are ideal vehicles to improve the effect of drugs (antibiotics, growth factors, etc.) aimed at wound healing [28].

Metal nanoparticles such as gold and silver are emerging as attractive biomaterials for targeting soft tissues [27]. Silver, gold, and copper nanoparticles, as well as titanium and zinc oxide nanoparticles, have shown potential therapeutic effects on wound healing [28]. Silver nanoparticles have exhibited good anti-inflammatory properties. Results demonstrated promotion of wound healing by silver through reduction of cytokine-modulated inflammation [29]. Others showed that silver nanoparticles impregnated in guar gum alkylamine yielded a faster wound-closing rate compared to other 


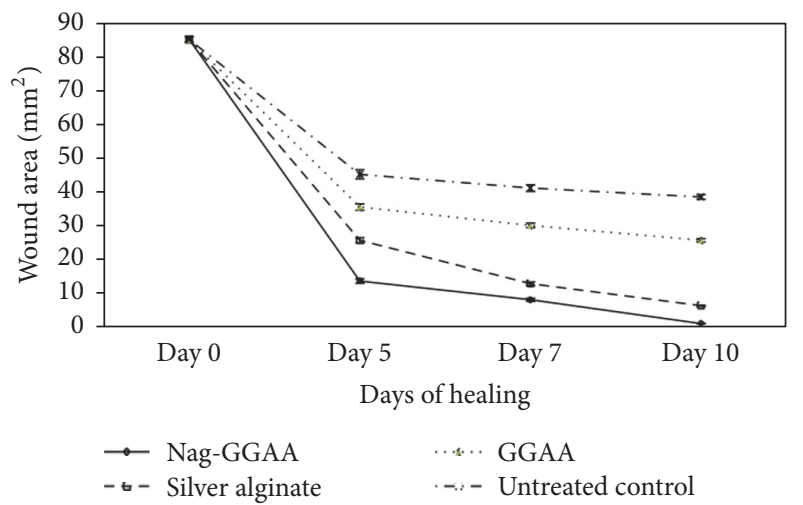

(a)

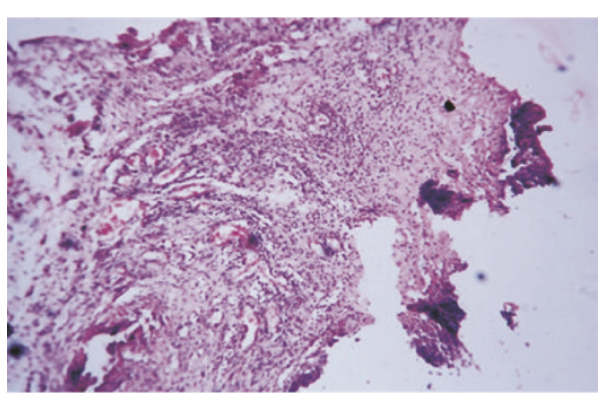

(b)

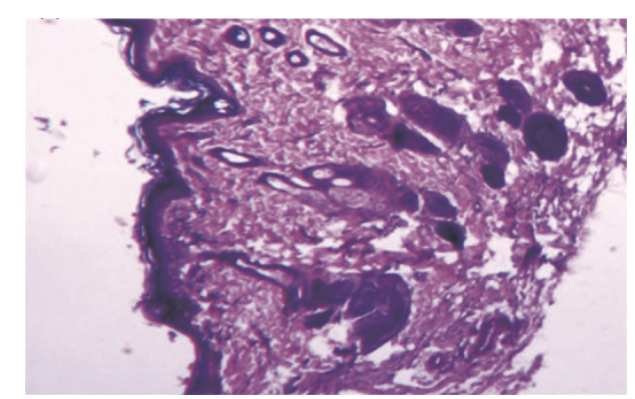

(c)

Figure 2: (a) Effect of wound closure on silver alginate guar gum alkylamine nanoparticles and other positive controls, (b) histological examination of control (without treatment) tissue, and (c) histological examination of tissue treated with silver alginate guar gum alkylamine nanoparticles [26] (figure obtained from an open access article distributed under the Creative Commons Attribution License).

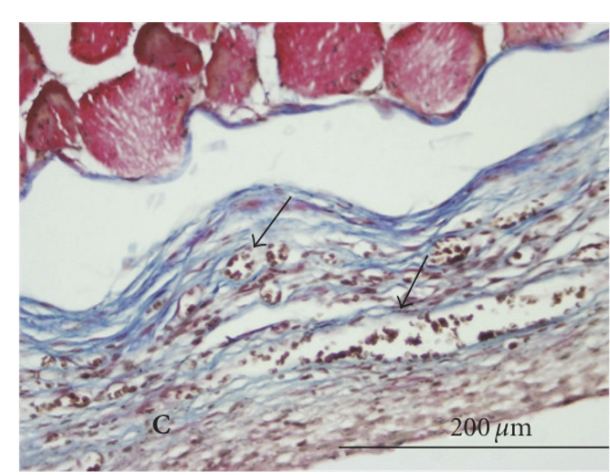

(a)

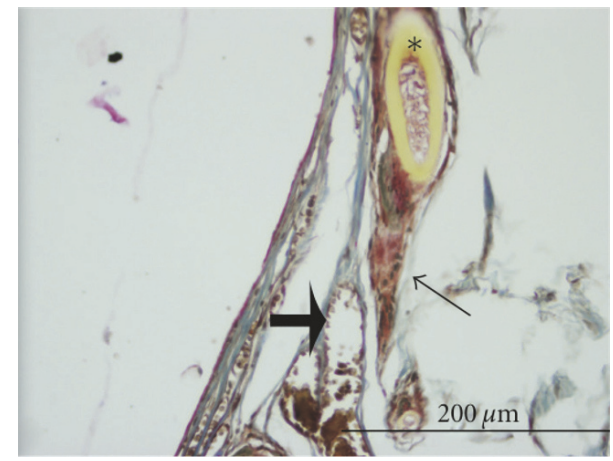

(b)

FIGURE 3: (a) Histological examination of wound tissue after applying gold/polypropylene/poly(ethylene glycol)2000 nanoparticles where arrows indicate inflammatory cells and newly formed blood vessels. C refers to capsule formation after applying the dressing. (b) Histological examination of wound tissue after applying gold/polypropylene/poly(ethylene glycol)4000 nanoparticles where thick arrow indicates neovascularization and thin arrow indicates giant cell accumulation [27] (figure obtained from an open access article distributed under the Creative Commons Attribution License).

positive controls, while histological examination revealed well-organized granulation tissue and epithelialization (Figure 2) [26]. Gold-nanoparticles-embedded biodegradable PEG polymers have been found to possess favorable soft tissue response causing less inflammation as the number of PEG side chain increases (Figure 3) [27]. Nitric oxide nanoparticles have also demonstrated a broad spectrum of antibacterial properties against both Gram-positive and Gram-negative bacteria [30]. Nitric oxide nanoparticles have also been shown to exert beneficial secondary effects on the healing process by modulating inflammation, angiogenesis, and tissue remodeling [31]. Since wounds are known to be deficient in nitric oxide, application of nitric oxidereleasing silica nanoparticles may accelerate healing by killing 
bacteria and overcoming the general nitric oxide deficiency [32].

Gong et al. [33] have shown that when curcumin was loaded onto the lipophilic core of a polymeric micelle dispersed in a hydrogel, this formulation exhibited adequate tissue adhesiveness and could release curcumin in an extended time period. Studies carried out by Jeschke et al. [34] and Pereira et al. [35] have focused on the liposomal delivery of keratinocyte growth factor (KGF) which stimulates epithelial cell differentiation and proliferation, processes of major importance in wound healing. This liposomal formulation constructed as a nonviral KGF cDNA gene complex extensively improved epidermal regeneration and improved epidermal cell net balance by increasing skin cell proliferation and decreasing skin cell apoptosis. The fabrication of a fusion protein comprising of elastin-like peptides and KGF resulting into a self-assembled nanoparticle (chimeric nanoparticle) enhanced the reepithelialization and granulation, two crucial processes in wound healing [36]. To overcome bacterial antibiotic resistance, Geilich et al. developed silver nanoparticles-embedded polymersomes [37]. This polymersome formulation constructed from a biodegradable diblock copolymer carrying silver nanoparticles embedded in the hydrophobic compartment and ampicillin in the hydrophilic compartment inhibited the growth of ampicillin-resistant Escherichia coli. Formulated nanoemulsions have been used to evaluate the mechanism of action associated with membrane damage. The skin irritation activity and wound healing results of the formulated nanoemulsion indicated the nonirritant nature of the formulation and higher wound contraction rate when compared to the free drug counterpart [38]. Solid lipid nanoparticles have been evaluated for their potential to prolong opioids release for pain reduction in severe skin wounds [39]. Recombinant human epidermal growth factor- (rhEGF-) loaded nanostructured lipid carriers can present an important alternative in the treatment of chronic wounds since this formulation has been reported to improve the wound healing quality expressed in terms of number of arranged microvasculature, fibroblast migration and proliferation, collagen deposition, and evolution of the inflammatory response [40].

Poly(lactic-co-glycolic acid) (PLGA) has been widely investigated for the fabrication of polymeric nanoparticles due to its advantages including biodegradability, biocompatibility, nontoxicity, and approval from regulatory agencies [28]. Studies on the delivery of the peptide LL37 (an endogenous peptide controlling wound healing and angiogenesis) from PLGA nanoparticles hypothesized that a combination of sustained release of lactate (to induce angiogenesis) and LL37 would promote wound closure [41].

To evaluate the role of nanosized recombinant human erythropoietin (rhEPO) in wound healing, the effects of subcutaneous injections of EPO on skin regeneration after deep second-degree scalding injuries were investigated [42]. Results indicated that nanosized rhEPO increased the rate of reepithelialization of the scalding injury and reduced the time to final wound closure. Silver-containing wound dressings are an integral part of wound therapy due to the antimicrobial effect of silver [43]. When nanocrystalline silver wound dressing was applied on major full-thickness scald in male rats, higher silver levels was measured in various organs and tissues than the controls. Silica or iron oxide nanoparticles by nanobridging (i.e., adhesion by aqueous nanoparticle solutions) have been reported to achieve rapid and strong closure and healing of deep wounds in skin and liver [44]. Bleeding control and tissue repair by nanobridging have been evaluated on liver which could eventually be utilized to test on spleen, kidney, heart, and lung surgeries. For skin wounds, remarkably aesthetic healing was obtained. When tight sealing is needed, nanobridging could complement anastomosis and classical suturing procedures [44].

Magnetic-based systems utilizing superparamagnetic nanoparticles have been tested for enhancing tissue regeneration [45]. For magnetic nanoparticles localization, soft tissues are significantly more complex than biological fluids. The magnetic force and magnetic nanoparticle characteristics will dictate the magnetic nanoparticle transport mechanism and distribution in soft tissues. Therefore, it is vital to determine these parameters in order to efficiently transport and localize magnetic nanoparticles in soft tissues and achieve the most therapeutically desirable magnetic nanoparticles distribution in the target area.

Nanoparticles can stick together cells that are inherently nonadhesive, thereby assembling dispersed single cells into large cohesive aggregates called nanostickers. In a study, authors have shown that $20 \mathrm{~nm}$ carboxylated polystyrene nanoparticles were more efficient nanostickers than $20 \mathrm{~nm}$ silica nanoparticles which were reported to induce fast wound healing and to glue soft tissues [46]. As metastasis is often related to a decrease of cell-cell adhesion, nanostickers will have the potential to reduce the escape of cells from tumors. They will also slow down the spreading of tumors which would result from a competition between cellsubstrate and cell-cell adhesion. By increasing the cohesion of tissues and organs, nanostickers may have important applications in tissue engineering and cancer treatment.

Hydroxyapatite is being extensively used as bone substitute materials for reconstructive surgery of the skeleton. The similarity of its chemical composition to the natural bone apatite is believed to be the reason for its very good biocompatibility and a direct, chemical bonding of bone tissue forming a biological and mechanical stable interface. The use of powders with small grain size could overcome the disadvantages of solid implants and lead to resorbable biomaterials for temporary substitution of skeletal defects. In one study, by using nanocrystalline hydroxyapatite suspension implant, a direct bone contact as well as inclusion into soft tissue along with partial resorption of the nanocrystalline hydroxyapatite was observed. In situ the nanocrystalline material mostly formed densely packed agglomerates which were preserved once included in bone or connective tissue [47]. In another study, the bone tissue response after the application of an oily calcium hydroxide suspension into defects created in the tibial bone was evaluated. The application of this oily suspension into tibial defects was inferior to venous blood alone but showed biocompatibility, decent resorption, and new bone formation [48]. 
3.2. Nanofibers. Electrospun nanofibers have become a widely utilized technique to produce nonwoven fiber mesh consisted of continuous fibers with diameters in the range of several nanometers to micrometers. Shortly after the development of using electrostatic forces to produce fibers in the 1930s [49], fibers being drawn from an external electric field are adopted in many engineering fields including filtration [50], protective fabrics [51], sensors [52], and energy-related applications [53]. Due to its popularity, the process conditions and solution variables used in electrospinning have been extensively reviewed by others on their roles in fiber diameters, morphologies, architectures, and mechanical properties [54-56]. Recently, the mechanical and biological cues from electrospun nanofibers provide potential applications in the biomedical field. In particular, there have been several comprehensive reviews on electrospinning and their applications in tissue engineering and drug delivery, especially for wound healing applications [57-61]. In this section, we narrow our discussion on drug delivery using electrospun materials and review the effect of release kinetics in promotion of soft tissue repair in wound healing. Specifically, we address several advantages and key aspects of using electrospun nanofibers as dressing materials in wound healing from processing, structure, and property relationships of the fiber materials.

Electrospinning is a fairly simple process that utilizes rapid solvent evaporation during fiber formation. Fibers can be collected on a stationary collector for nonwoven fiber structure or on a rotating mandrel for aligned fiber structure [62]. Fibers can be produced by a coaxial or even triaxial nozzle to enable the core-shell structure $[63,64]$. Others demonstrated the possibility of pharmaceutical scaleup during the production of fiber mesh [65]. Since electrospinning accepts a broad range of polymer solutions and small molecules, design and manufacturing of blend fibers or natural fibers that incorporate various small molecules or bioactive agents become possible. For example, blend fibers of poly( $\varepsilon$-caprolactone)(PCL) and gum tragacanth (GT) were loaded with curcumin (Cur) (up to $24 \mathrm{wt} \%$ ) as a dressing material to provide antioxidant, antitumurogenic, and antiinflammatory ability $[66,67]$. At $3 \mathrm{wt} \%$ curcumin loading, results showed that PCL/GT/Cur nanofibers released $65 \%$ of the drug after 20 days, whereas wound closure rates in a mouse model significantly improved with the use of PCL/GT/Cur dressings, including those preseeded with mesenchymal stem cells on the nanofibers. In another study, collagen nanofibers were electrospun from tilapia skin for wound healing materials [68]. According to the in vitro results, nanofiber mesh was biocompatible with human keratinocytes while cell proliferation increased when using collagen nanofibers as compared to control groups (borosilicate glass). In addition, collagen fibers appeared to increase wound closure rate significantly even when comparing to those subjected to commercially available dressing materials, Kaltostat. Furthermore, studies showed the immobilization of the peptide motif (Cys-KR12) on silk fibroin nanofibers and suggested a strong antimicrobial effect to several pathogenic bacterial strains [69]. Moreover, chitosan and poly(ethylene oxide) (PEO) blend solutions were electrospun into fibers to incorporate vascular endothelial growth factor (VEGF) while platelet-derived growth factor-BB (PDGF-BB) was encapsulated in poly(lactic-co-glycolic acid) (PLGA) nanoparticles and further loaded in nanofibers during electrospinning process [70]. Results suggested that VEGF achieved near $100 \%$ release in $24 \mathrm{~h}$ due to the presence of water soluble PEO in the polymer matrix, whereas PDGF-BB released only $40 \%$ from the PLGA nanoparticles after $168 \mathrm{~h}$. According to the authors, programmable release of dual growth factors received an improved wound closure rate over 4 weeks on a rat model as compared to a pharmaceutical dressing material, Hydrofera Blue. In another study, PLGA/CuO hybrid nanofibers were electrospun into fibrous scaffolds for antibacterial properties (Figure 4(a)) [71]. With the addition of $\mathrm{CuO}$ in the fibers, inhibition of Escherichia coli and Staphylococcus aureus decreased significantly (Figure 4(b)). Results suggested that release of the $\mathrm{Cu}^{2+}$ ions attributed to the antibacterial performance (Figure 4(c)). The PLGA/CuO fibers promoted NIH3T3 cells proliferation (Figure 4(d)) and did not suggest high level of cytotoxicity effect. These examples demonstrate the feasibility and advantages in using electrospun nanofibers as dressing materials for wound healing applications while the diversity of choices in polymer and $\mathrm{drug} / \mathrm{bioactive}$ agent combinations is endless.

In addition to the ease of production, the structure of electrospun fiber mesh is ideal for wound dressing materials due to high surface area to volume ratio. This advantage was illustrated in a study suggesting that the rate and the extent of blood coagulation depended on the surface area available for blood to react on before forming clot [73]. Specifically, according to the authors, a $60 \times 60 \times 0.7 \mathrm{~mm}$ nanofibrous mesh with an average fiber diameter of $700 \mathrm{~nm}$ had a surface area of around $3300 \mathrm{~cm}^{2}$, which was about 40-50-fold higher than a solid film of the same dimension. The high surface area of the fiber mesh also provides high water absorption ability. For example, comparing to a typical film dressing, water absorption ability of nanofiber mesh increased 10-100-fold, depending on the polymer employed [74]. Furthermore, the porous structure of the nanofiber mesh provides oxygen permeability and flow of the nutrients for cell respiration and proliferation while separating bacteria from outside environment. The control of the fluid flow allows the hydration and cleanliness of the wound. Finally, the porous structure of the nanofiber mesh provides an idea environment to stimulate cellular response due to its structure similarity to extracellular matrix. As a result, cells can be physically supported by the nanofiber mesh while their attachment, migration, proliferation, and differentiation are upregulated in wound healing process [75]. Therefore, the structure of nanofiber mesh is advantageous as a dressing material for wound healing.

Perhaps the most important factor that the nanofiber mesh can provide is their excellent properties, such as conformability, mechanical properties, and functional abilities. Considering this factor, gel dressings provide some degree of conformability without any mechanical support to cells and tissues. By contrast, film dressings provide some level of mechanical support to the tissues at wound site but have very limited conformability. Therefore, current trends in dressing materials have been focused on electrospun 


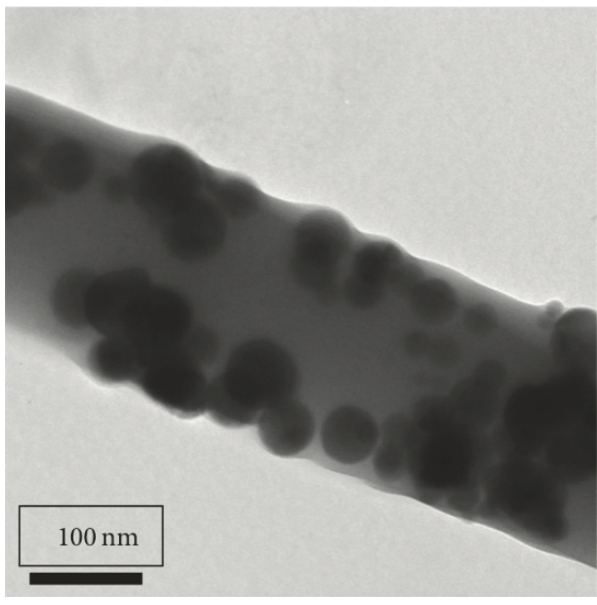

(a)

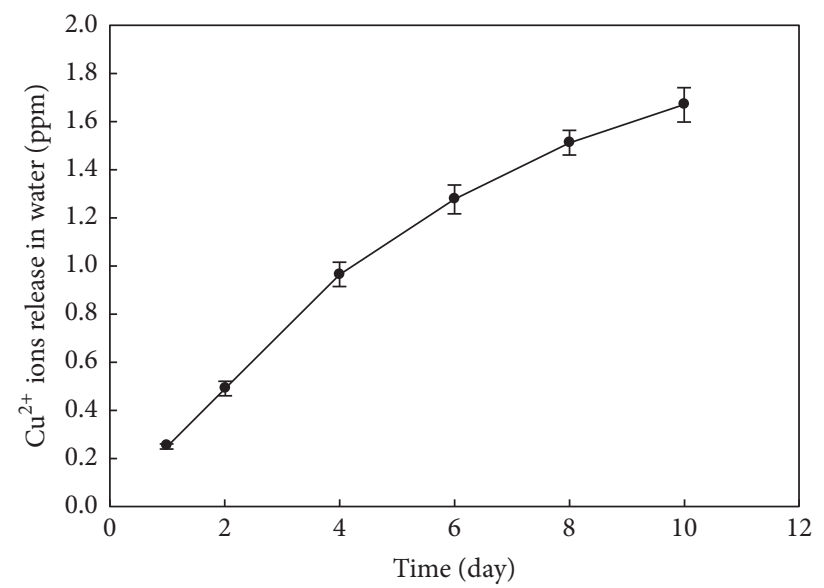

(c)

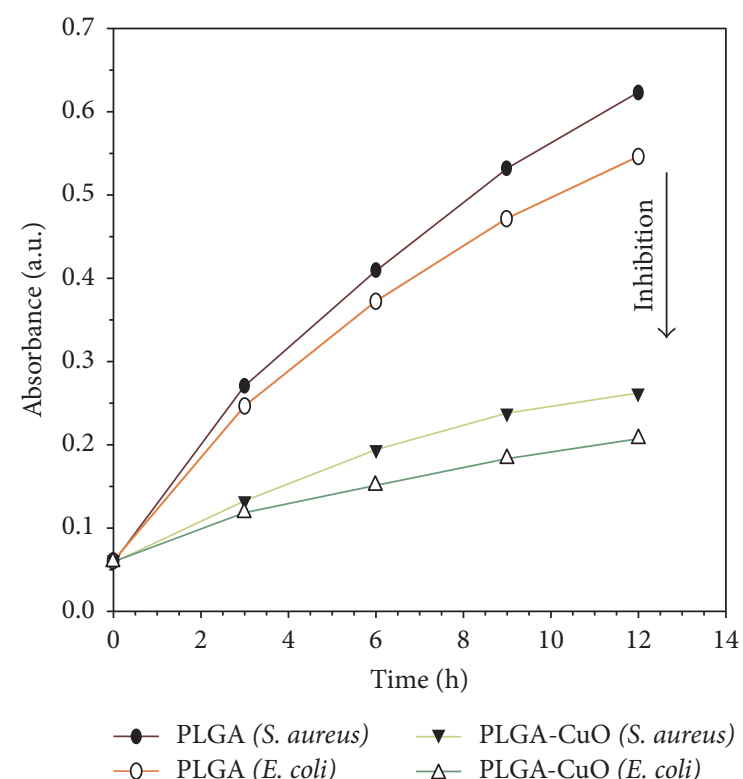

(b)

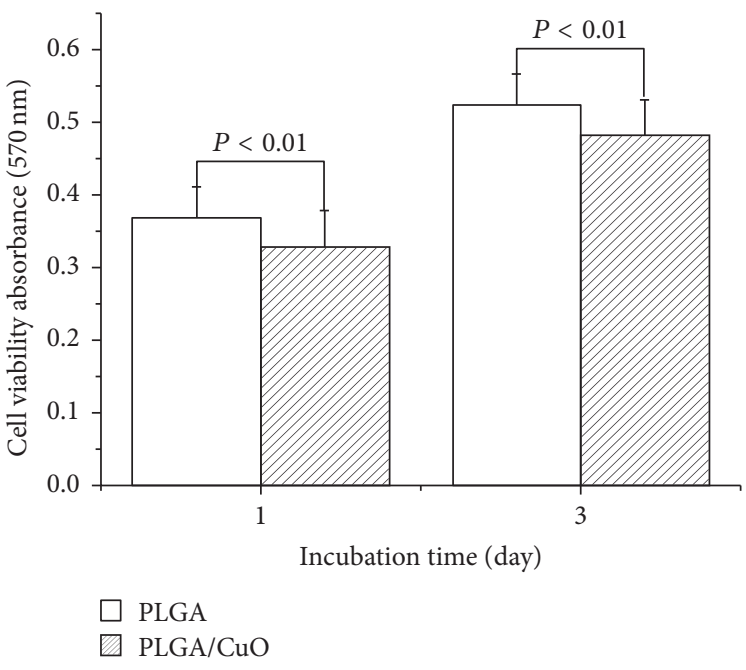

(d)

Figure 4: (a) CuO nanoparticles embedded in electrospun PLGA fibers, (b) inhibition of E. coli and S. aureus from PLGA and PLGA/CuO fibers, (c) release profiles of $\mathrm{Cu}^{2+}$ ion in water, and (d) fibroblast cell viability study from PLGA and PLGA/CuO fibers [71] (figure obtained from an open access article distributed under the Creative Commons Attribution License).

nanofibers due to excellent conformability while providing mechanical support to cells/tissues resulting in a better coverage at locations with complex 3D contours and improved protection of the wounds during body movement. For example, development of artificial skins requires high degree of conformability, and this was done by using two interlocking elastic patterned nanofibrous membranes [76]. In terms of mechanical properties, again depending on the choice of based polymer, nanofiber mesh can achieve a broad range of elastic stiffness, tensile strength, and elongation to failure. In one particular review, nanofibers with high stiffness $(>1 \mathrm{GPa})$ and high strength $(>0.1 \mathrm{GPa})$ fibers were discussed [77]. Others have reported the mechanical properties of polyester nanofibers before and after drug loading as well as the mechanical performance of the fibers during drug release and degradation phases [78]. In another study, electrospun blend chitosan/PEO nanofibers showed excellent properties in the inhibition of Staphylococcus aureus [72]. According to the authors, increasing chitosan content in the chitosan/PEO fibers increased mechanical properties (Table 1 ). While a $60 \%$ weight remaining of the chitosan/PEO (1/1) fibers was observed (Figure 5(a)), only the chitosan/PEO (2/1) fibers exhibited the best antibacterial properties (Figure 5(b)). All fiber formulations promoted L292 fibroblasts proliferation (Figure 5(c)), suggesting a good biomaterials to enhance wound healing. With respect to functional ability, not only do electrospun nanofibers have the ability to carry small molecule drugs $[79,80]$, biological active components 
TABLE 1: Mechanical properties of chitosan/PEO blend fibers at various rations.

\begin{tabular}{lccc}
\hline Mass ratio & $\begin{array}{c}\text { Young's modulus } \\
(\mathrm{MPa})\end{array}$ & $\begin{array}{c}\text { Tensile strength } \\
(\mathrm{MPa})\end{array}$ & $\begin{array}{c}\text { Strain at break } \\
(\%)\end{array}$ \\
\hline $2: 1$ & $24.6 \pm 6.5$ & $2.8 \pm 1.0$ & $14.7 \pm 2.5$ \\
$1: 1$ & $14.0 \pm 3.5^{*}$ & $1.1 \pm 0.5^{\#}$ & $10.7 \pm 4.6$ \\
$1: 2$ & $9.1 \pm 4.2^{*}$ & $0.9 \pm 0.4^{\#}$ & $11.7 \pm 3.6$ \\
\hline
\end{tabular}

${ }^{*} P<0.05$, Young's modulus comparisons made to $2: 1$ mass ratio scaffolds. ${ }^{\#} P<0.05$, tensile strength comparisons made to $2: 1$ mass ratio scaffolds.

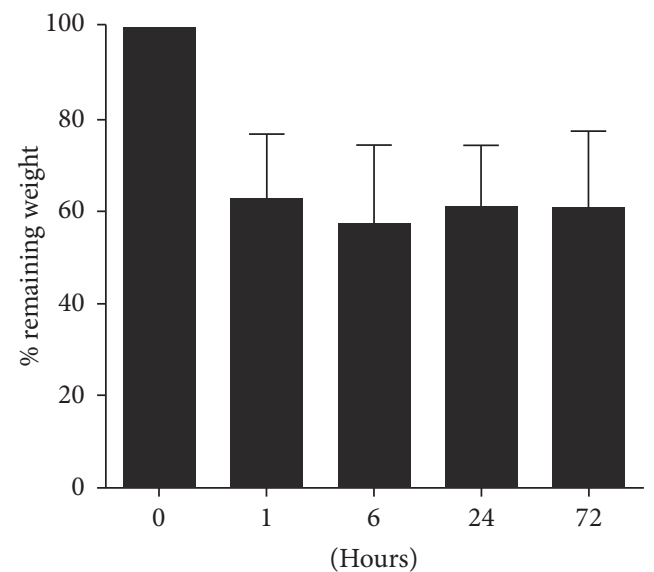

(a)

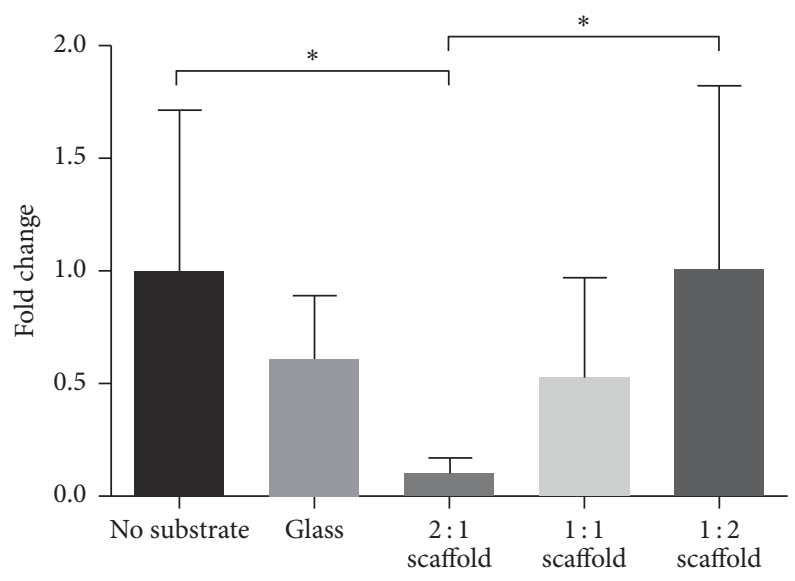

(b)

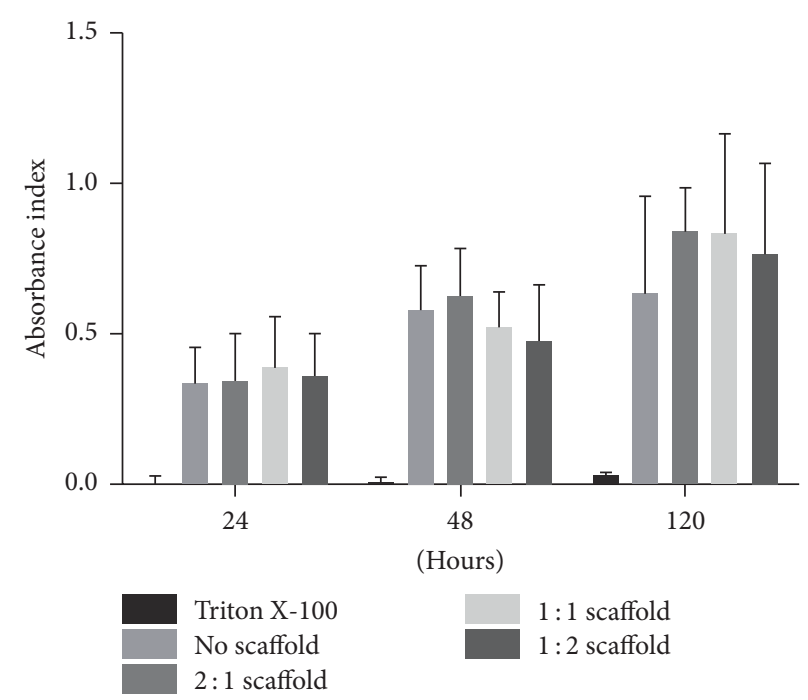

(c)

FiguRE 5: (a) Fiber degradation profile, (b) antibacterial properties of the fibers expressed in fold increase of bacteria, and (c) fibroblast proliferation rate on blend fibers [72] (figure obtained from an open access article distributed under the Creative Commons Attribution License). * indicates statistically significant differences $\left({ }^{*} P<0.05\right)$.

(e.g., growth factors [81], proteins and enzymes [82], and genes [83]), and even cells, but also their surface can be functionalized with signaling molecules to promote cell activities [84]. This makes electrospun nanofibers a multifunctional drug delivery system. Given that one of the goals in wound healing is to achieve scar free, electrospun nanofibers possess the ability to achieve this functional ability. For example, by promoting the skin to grow immediately while giving cells a better road map for self-repair, it is possible to achieve scar free in wound healing [85]. Therefore, electrospun nanofibers, utilizing modern nanotechnology, are able to provide solutions to chronic wounds and/or nonhealing wounds.

3.3. Surface Nanofeatures. Topographic patterns of a biopolymer substrate are known to affect cellular responses such as adhesion, migration, proliferation, and differentiation. Many studies have discussed the optimal topographical feature and/or surface properties to instruct cell faith. In particular, 
biological tissues display a wide variety of behaviors due to varying topographical features such as fibrils, pits, pillars, fiber bundles, and protrusions in dimensions of tens of nanometers up to micrometers [86-88]. These reported surface topographies are crucial in guiding the cellular behaviors such as spreading, migration, and adhesion [87, 89]. Given that topographic signal presentation is one of the paths that the nature uses to give cells specific orders, current status in this area of work typically focuses on using nanotechnology to produce engineered surface features from biopolymer films so that these substrates can further control cellular behaviors. Many studies have already shown that patterned substrates strongly influence cell migration, adhesion, proliferation, and differentiation, indicating that the presence of topographic signals can be a powerful tool to promote tissue regeneration [89-93].

Getting to know the fundamental mechanisms of cellular response as a result to the topographical features and/or surface properties will improve the understanding in how to regulate cellular functions. The way to understand biological functions from cells is to analyze their responses over different topographical aspects. In a study, micropatterned substrates exhibiting convex and concave architectures were used to investigate the behaviors and functions of human epithelial cells [94]. Results showed that cell densities and distribution significantly increased at the transitions of the convex and concave features when comparing to a flat unpatterned substrate. In addition, time-lapse observations suggested convex and concave patterns promoted variations in cell migration due to different mechanisms. According to the study, cells migrated towards the sidewall of a convex substrate while sidewalls and bottom migration were observed on concave substrate. Furthermore, the study reported the expression of E-cadherin on cell adhesion to the micropatterned substrates after $144 \mathrm{~h}$. Results suggested that cells expressed E-cadherin on the engineered film substrate with nanofeatures similar to the surface with no pattern. In addition, cells displayed a more spread pattern such as monolayers which displayed low levels of E-cadherin, suggesting that the surface nanofeatures of biopolymer films were able to regulate gene expression of human epithelial cells. In general, surface nanofeatures of a substrate promote cellular spatial growth with an increased cell density and homogeneous distribution suitable for tissue regeneration.

In wound healing, the regenerative response in the initial stage from cells is the most important event associated with wound-closing rate. Wound healing involves a series of physiological process generated from cells, where the nature of complexity in wound healing makes it potentially difficult to control the occurrence of many abnormalities. Such complexity involves cellular interactions, biochemical responses to the dressing materials, and several active enzymatic pathways that govern the healing process of the tissue [95]. Natural and synthetic polymeric materials like gels, films/substrates, composites, and other micro/nanocomposites have been used in tissue regeneration for wound healing. While nanofibrous materials contain high surface area, which is also a great candidate to serve as carriers for biological agents in wound healing, researches have shown that films/substrates promote wound healing in tissue regeneration process. Current status in biopolymer film dressings focuses on providing optimal healing conditions considering all the healing mechanisms [96].

In some studies, natural polymers were used for treatment of different ailments. For example, chitosan and gelatin films have been used in wound dressing materials with excellent wound healing properties [96-98]. These composite films were made with increased gelatin concentration and were examined for thickness, folding endurance, water absorption capacity, tensile strength, and other biological properties such as antimicrobial activity. Results showed that increasing gelatin concentration in the composite films increased folding endurance, thickness, tensile strength, and water absorption capabilities. Wound closure rate was also improved comparatively due to the presence of gelatin. Percentage of wound contraction was significantly enhanced when using chitosan/gelatin composite films. Others showed that chitosan-hydrogel coated grafts, on the UV light irradiation linkage, exhibited a resistance against Escherichia coli in vitro and in vivo. The chitosan-hydrogel acted directly as an antibacterial biomaterial on a Dacon graft and was able to inhibit the infection [99]. In another study, sponges made from chitosan glutamate and sericin were used for the development in treatment of chronic skin ulcers. The sericin content in the dressing exerts a protective effect on human fibroblasts against oxidative damage. Furthermore, the optimized dressing is also able to improve the fibroblast proliferation and improve wound healing [100].

Studies showed that the US military has put in great effort to develop rapid acting haemostatic agents [102]. The core agent was a Zeolite based composite that can be used to stabilize the bleeding of the wound of the victim. This material has an interesting character, which has a high affinity with water so it absorbs all the water content in the blood of the victim. However, the issue with the composite dressing in this case is that its high affinity towards water released high energy causing the burn out of surrounding tissues. As a result form this study, current efforts have been focused on developing new biocompatible materials which has an ability to induce hemostasis and improving tissue regeneration. Bioactive glass has been identified as a quick acting haemostatic agent, which helps in clotting blood along with reducing the burning the healthy tissues.

In some research works, silk fibroin films were used as wound dressing materials [103-105]. They are of particular biomaterials, which have wide range of applications in ophthalmic diseases due to their transparent nature, mechanical properties, and least possible inflammatory response upon implantation. Freestanding silk films having parallel line and concentric ring topographies were created for in vitro characterization of human corneal limbal-epithelial (HCLE) cell response upon the varying geometric surfaces. These topographical patterns from silk fibroin films affected the initial HCLE culture substrate attachment, cellular alignment, actin cytoskeleton alignment, and focal adhesion localization. In addition there is distant localization of focal adhesion formation on the edges for all the silk pattern topographies. Most importantly, surface features and topographies from 

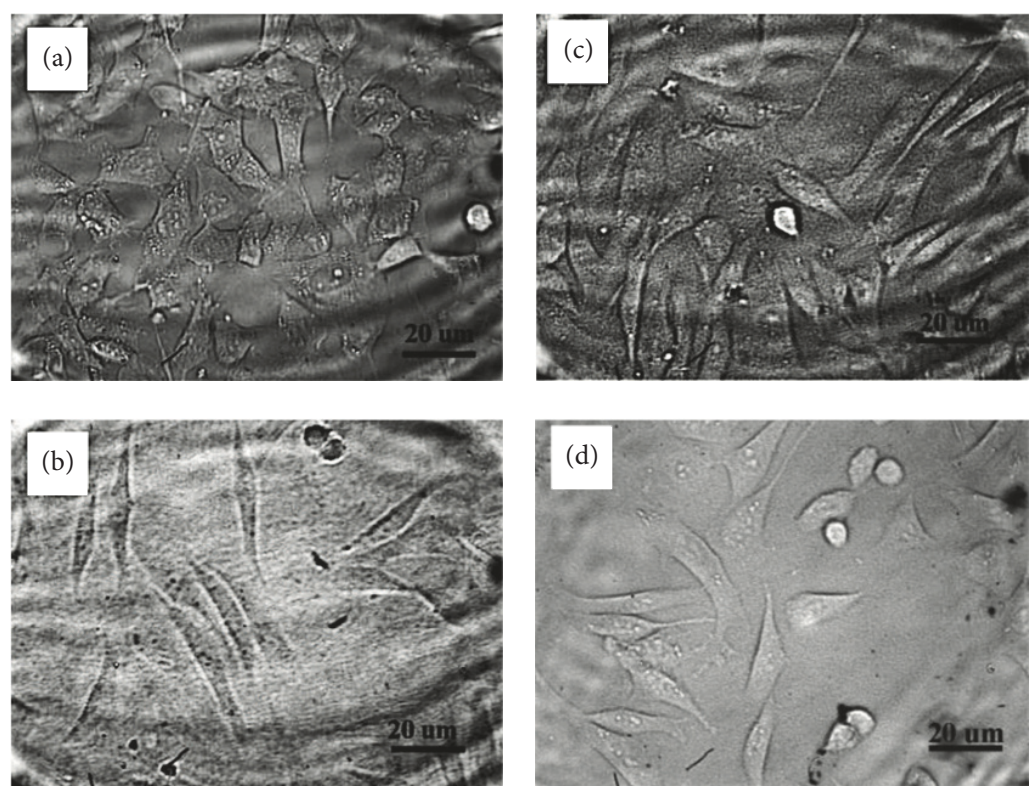
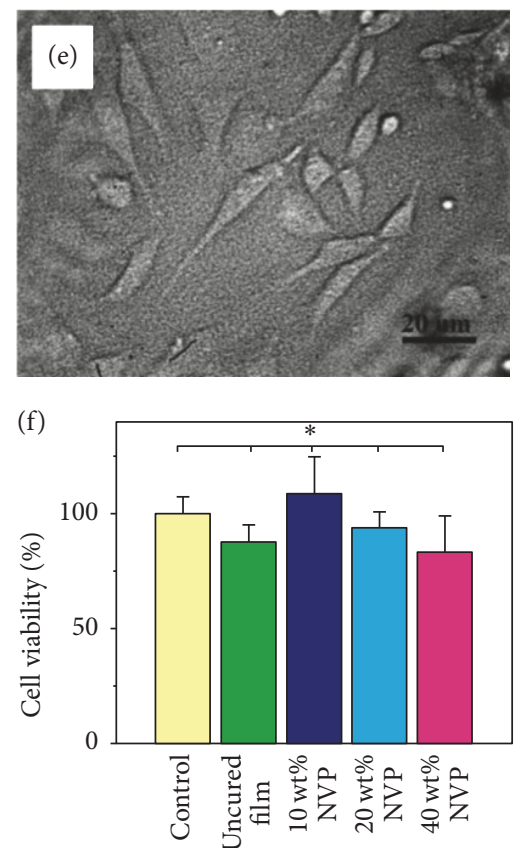

FIGURE 6: (a)-(d) Cell attachment of control, uncross-linked blend films of chitosan/pEGF (80/20) and cross-linked blend films of chitosan/pEGF (80/20) at $10 \mathrm{wt} \%, 20 \mathrm{wt} \%$, and $40 \mathrm{wt} \%$ of NVP cross-linker, respectively. Viability study of the mouse fibroblasts on the corresponding substrates [101] (figure obtained from an open access article distributed under the Creative Commons Attribution License). * indicates statistically significant differences $\left({ }^{*} P<0.05\right)$.

silk fibroin films seemed to help direct corneal epithelial cell response and actin cytoskeleton alignment, with respect to the focal adhesion distribution in vitro.

Others showed the preparation of polymer blends with synthetic resins and natural biopolymers for wound dressing purposes. The general requirements for the main use in soft tissues are their biocompatibility, nontoxicity, and being not causing secondary trauma to the wound. To attain all these properties, the use of a polymer blend is better due to the contribution of properties from both polymers [101]. Results showed that chitosan had excellent intrinsic properties, and it exhibited biocompatibility, biodegradability, nonantigenicity, and nontoxicity. Therefore, chitosan is a very popular based material for wound dressing. However, chitosan requires a few modifications due to its inferior mechanical properties. Hence, the study suggested the preparation of blend chitosan/polyethylene glycol fumarate as a potential candidate for wound dressing material. Due to its unsaturated feature, the composite films contain excellent biocompatibility and biodegradability while being photocured with visible light irradiation. In similar studies, chitosan and precursor epidermal growth factor (pEGF) were prepared through photocuring with analyses of the film properties for wound dressing applications [106-108]. The cross-linking of pEGF in chitosan matrix resulted in semi-interpenetrating network of hydrogels. The effect of $N$-vinyl pyrrolidone (NVP) $(10,20$, and $40 \mathrm{wt} \%$ relative to PEGF) as diluent and cross-linking agent had a significant effect on degree of conversion, which further affected the attachment of mouse fibroblast cells (L929) and their viability (Figure 6) [101]. With the increase in NVP concentration in feed from 10 to $20 \mathrm{wt} \%$, percentage of degree of conversion increased; while adding more NVP (up to $40 \mathrm{wt} \%$ ), it decreased. Films that were cross-linked provided a suitable $3 \mathrm{D}$ environment allowing cells to anchor, grow, and proliferate due to the increase of proper sites. Cells were viable after $24 \mathrm{~h}$ of the culture. This may serve as an alternative strategy towards in vitro culture of the cells that can be further grafted onto the wound site.

\section{Future Directions}

Biomaterials play an important role in the treatment efficacy and outcomes of various disease states. As a carrier material, drug loading and drug release mechanisms are critical determinants in providing suitable health care to chronicle or nonhealing wound patients. With the improvement in nanotechnology, biomaterials as drug carriers have made a significant improvement in medicine. Currently, nanotechnology-based biomaterials have started to emerge as the main stream in wound dressings with the benefits to significantly decrease the issue in frequent changing of the dressing materials. Ultimately, provided the nanotechnology has the ease in fabrication and is readily available for customization, the future of wound dressing using nanotechnology-based biomaterials will focus on personalization using a particular prescribed treatment plan. To be able to achieve this goal, there are still numerous challenges in research that require attention. For example, one particular research question is to address on the encapsulation large macromolecules using the current known nanotechnologies [109]. These macromolecules provide additional treatment benefits along with the small 
molecule drug, providing dual-function treatment mechanism. Furthermore, modulating small molecule drug release with the addition of large macromolecules has not been fully studied yet, which is a promising area that may require the combination of two different nanotechnologies (e.g., nanoparticles/liposome and nanofibers) together to provide programmable treatment plan. In 2014, a proof of concept of using micelles incorporated nanofibers had been shown effectively in promotion of skin tissue regeneration while exhibiting a good biocompatibility to support adipose-derived stem cells proliferation [110]. While other similar publications are rare, the next generation of wound dressing materials requires integration of two or more nanotechnology-based biomaterials.

Another specific area that may benefit from nanotechnology is gene therapy. In particular, nanotechnology-based biomaterials have the potential to deliver and repair gene in a way that the current modern clinical procedures experience limitations. To be able to interact and communicate with cells and tissues to perform gene delivery or repair, the mechanical stability and biocompatibility of the biomaterials require a new level of design and manufacturing. This is where nanotechnology will come in handy, as such adjustments are fairly flexible with different manufacturing methods. Hence, the future trend of biomaterials (e.g., metals, ceramics, and polymers) will have a much superior mechanical properties and the excellent biocompatibility and biofunctionality to achieve the most desirable pharmaceutical performance of the implants.

Nanotechnology is a multidisciplinary field where scientists and engineers will need to work together for a particular design and manufacturing of the biomaterial. This collaborative work involves the understanding of molecular biology, biochemistry, genetics, physics, materials science, and other areas of sciences and engineering departments for application that will integrate the design and manufacturing of multifunction biomaterials for wound healing.

\section{Conclusions}

In summary, this brief review provides current status on the involvement of nanotechnology in the fabrication and applications of biomaterials. In particular, biomaterials in the forms of nanoparticles/micelles/lipids, nanofibers, and films/substrates with surface nanofeatures were discussed with respect to wound healing. The understanding of release mechanism of small molecule drugs and large macromolecules from these nanotechnology-based biomaterials has significantly improved the healing conditions for chronicle and nonhealing wound patients. In addition, interactions between cells and biomaterials enable the regeneration of tissues. Given that nanotechnology plays an important role in the development of novel biomaterials, the next generation of the wound dressing materials will further utilize nanotechnology to improve the properties of the dressing materials as well as enhance the healing process. Overall, this review emphasizes the contribution of nanotechnology in modern functionalized biomaterials.

\section{Conflicts of Interest}

The authors declare that there are no conflicts of interest regarding the publication of this paper.

\section{Authors' Contributions}

All authors contribute to the manuscript equally. In particular, Mhd Hussam Hijazi Kiellani contributes to Section 2, Simi Gunaseelan contributes to Section 3.1, Venkata Vamsi Krishna Thottempudi contributes to Section 3.3, and Shih-Feng Chou contributes to all other sections. Pierre Neuenschwander and Huarong Nie contribute to intellectual discussions of the topics and review of the manuscript.

\section{Acknowledgments}

This work is supported by a grant from the Office of Sponsor Research at the University of Texas at Tyler awarded to ShihFeng Chou (21001323). The authors thank Dr. Qingsong Jiang for critical review of the manuscript.

\section{References}

[1] C. Paddock, "Nanotechnology in medicine: huge potential, but what are the risks?" Medical News Today, accessed on 2/8/2017, http://www.medicalnewstoday.com/articles/244972.php.

[2] European Commission, Scientific Committee on Emerging and Newly Identified Health Risks (SCENIHR). Opinion on "the scientific aspects of the existing and proposed definitions relating to products of nanoscience and nanotechnologies". Adopted. Brussels: European Commission; 29 November 2007.

[3] R. Valiev, "Materials science: nanomaterial advantage," Nature, vol. 419, no. 6910, pp. 887-889, 2002.

[4] D. Pal, P. Singh, and P. Mishra, "Composite ceria nanofiber with different copper loading using electrospinning method," Journal of Alloys and Compounds, vol. 694, pp. 10-16, 2017.

[5] G. Oberdörster, A. Maynard, K. Donaldson et al., "Principles for characterizing the potential human health effects from exposure to nanomaterials: elements of a screening strategy," Particle and Fibre Toxicology, vol. 2, 35 pages, 2005.

[6] V. Torres-Costa, "Porous silicon materials for biomedical applications," edited by H. A. Santos, pp. 185-222, 2014.

[7] T. M. Aminabhavi, S. P. Dharupaneedi, and U. A. More, "The role of nanotechnology and chitosan-based biomaterials for tissue engineering and therapeutic delivery," in Chitosan Based Biomaterials, J. A. Jennings and J. D. Bumgardner, Eds., vol. 2, pp. 1-29, 2017.

[8] G. M. Barratt, "Therapeutic applications of colloidal drug carriers," Pharmaceutical Science \& Technology Today, vol. 3, no. 5, pp. 163-171, 2000.

[9] D. Peer, J. M. Karp, S. Hong, O. C. Farokhzad, R. Margalit, and R. Langer, "Nanocarriers as an emerging platform for cancer therapy," Nature Nanotechnology, vol. 2, no. 12, pp. 751-760, 2007.

[10] H. Maeda, "The enhanced permeability and retention (EPR) effect in tumor vasculature: the key role of tumor-selective macromolecular drug targeting," Advances in Enzyme Regulation, vol. 41, pp. 189-207, 2001. 
[11] A. H. Touny and S. B. Bhaduri, "A reactive electrospinning approach for nanoporous PLA/monetite nanocomposite fibers," Materials Science and Engineering C, vol. 30, no. 8, pp. 13041312, 2010.

[12] S. Ramakrishna, R. Jose, P. S. Archana et al., "Science and engineering of electrospun nanofibers for advances in clean energy, water filtration, and regenerative medicine," Journal of Materials Science, vol. 45, no. 23, pp. 6283-6312, 2010.

[13] S. Ramakrishna, K. Fujihara, W.-E. Teo, T. Yong, Z. Ma, and R. Ramaseshan, "Electrospun nanofibers: solving global issues," Materials Today, vol. 9, no. 3, pp. 40-50, 2006.

[14] S. Liao, C. K. Chan, and S. Ramakrishna, "Electrospun nanofibers: work for medicine?" Frontiers of Materials Science in China, vol. 4, no. 1, pp. 29-33, 2010.

[15] J. M. Taboas, R. D. Maddox, P. H. Krebsbach, and S. J. Hollister, "Indirect solid free form fabrication of local and global porous, biomimetic and composite 3D polymer-ceramic scaffolds," Biomaterials, vol. 24, no. 1, pp. 181-194, 2003.

[16] T. Wang, Y. Wan, and Z. Liu, "Fabrication of hierarchical micro/nanotopography on bio-titanium alloy surface for cytocompatibility improvement," Journal of Materials Science, vol. 51, no. 21, pp. 9551-9561, 2016.

[17] S. A. Biela, Y. Su, J. P. Spatz, and R. Kemkemer, "Different sensitivity of human endothelial cells, smooth muscle cells and fibroblasts to topography in the nano-micro range," Acta Biomaterialia, vol. 5, no. 7, pp. 2460-2466, 2009.

[18] A. S. G. Curtis and C. D. W. Wilkinson, "Reactions of cells to topography," Journal of Biomaterials Science, Polymer Edition, vol. 9, no. 12, pp. 1313-1329, 1998.

[19] Y. Wang, B. Wang, G. Wang, T. Yin, and Q. Yu, "A novel method for preparing electrospun fibers with nano-/micro-scale porous structures," Polymer Bulletin, vol. 63, no. 2, pp. 259-265, 2009.

[20] A. Luwang Laiva, J. R. Venugopal, S. Sridhar, B. Rangarajan, B. Navaneethan, and S. Ramakrishna, "Novel and simple methodology to fabricate porous and buckled fibrous structures for biomedical applications," Polymer, vol. 55, no. 22, pp. 58375842, 2014.

[21] J. J. Norman and T. A. Desai, "Methods for fabrication of nanoscale topography for tissue engineering scaffolds," Annals of Biomedical Engineering, vol. 34, no. 1, pp. 89-101, 2006.

[22] D. Williams, "The relationship between biomaterials and nanotechnology," Biomaterials, vol. 29, no. 12, pp. 1737-1738, 2008.

[23] European Commission, Scientific Committee on Emerging and Newly Identified Health Risks (SCENIHR). Opinion on "the appropriateness of existing methodologies to assess the potential risks associated with engineered and adventitious products of nanotechnologies". Adopted. Brussels: European Commission; 10 March 2006.

[24] J.-H. Lee, K. Lee, M.-H. Lee, B. Kim, K. S. Chinannai, H. Hur et al., "Wound healing effects of Prunus yedoensis matsumura bark in scalded rats," Evidence-Based Complementary and Alternative Medicine, vol. 2017, Article ID 7812598, 7 pages, 2017.

[25] I. Tocco, B. Zavan, F. Bassetto, and V. Vindigni, "Nanotechnology-based therapies for skin wound regeneration," Journal of Nanomaterials, vol. 2012, Article ID 714134, 11 pages, 2012.

[26] R. G. Auddy, M. F. Abdullah, S. Das, P. Roy, S. Datta, and A. Mukherjee, "New guar biopolymer silver nanocomposites for wound healing applications," BioMed Research International, vol. 2013, Article ID 912458, 8 pages, 2013.

[27] D. B. Hazer, B. Hazer, and N. Dinçer, "Soft tissue response to the presence of polypropylene-G-poly(ethylene glycol) combtype graft copolymers containing gold nanoparticles," Journal of Biomedicine and Biotechnology, vol. 2011, Article ID 956169, 7 pages, 2011.

[28] F. Oyarzun-Ampuero, A. Vidal, M. Concha, J. Morales, S. Orellana, and I. Moreno-Villoslada, "Nanoparticles for the treatment of wounds," Current Pharmaceutical Design, vol. 21, no. 29, pp. 4329-4341, 2015.

[29] J. Tian, K. K. Y. Wong, C.-M. Ho et al., “Topical delivery of silver nanoparticles promotes wound healing," ChemMedChem, vol. 2, no. 1, pp. 129-136, 2007.

[30] F. DeRosa, M. R. Kibbe, S. F. Najjar, M. L. Citro, L. K. Keefer, and J. A. Hrabie, "Nitric oxide-releasing fabrics and other acrylonitrile-based diazeniumdiolates," Journal of the American Chemical Society, vol. 129, no. 13, pp. 3786-3787, 2007.

[31] E. M. Hetrick and M. H. Schoenfisch, "Reducing implantrelated infections: active release strategies," Chemical Society Reviews, vol. 35, no. 9, pp. 780-789, 2006.

[32] A. Soneja, M. Drews, and T. Malinski, "Role of nitric oxide, nitroxidative and oxidative stress in wound healing," Pharmacological Reports, vol. 57, Suppl: 108-199, 2005.

[33] C. Gong, Q. Wu, Y. Wang et al., "A biodegradable hydrogel system containing curcumin encapsulated in micelles for cutaneous wound healing," Biomaterials, vol. 34 , no. 27 , pp. $6377-$ 6387, 2013.

[34] M. G. Jeschke, G. Richter, F. Höfstädter, D. N. Herndon, J.-R. Perez-Polo, and K.-W. Jauch, "Non-viral liposomal keratinocyte growth factor (KGF) cDNA gene transfer improves dermal and epidermal regeneration through stimulation of epithelial and mesenchymal factors," Gene Therapy, vol. 9, no. 16, pp. 10651074, 2002.

[35] C. T. Pereira, D. N. Herndon, R. Rocker, and M. G. Jeschke, "Liposomal gene transfer of keratinocyte growth factor improves wound healing by altering growth factor and collagen expression," Journal of Surgical Research, vol. 139, no. 2, pp. 222228, 2007.

[36] P. Koria, H. Yagi, Y. Kitagawa et al., "Self-assembling elastin-like peptides growth factor chimeric nanoparticles for the treatment of chronic wounds," Proceedings of the National Academy of Sciences of the United States of America, vol. 108, no. 3, pp. 10341039, 2011.

[37] B. M. Geilich, A. L. Van De Ven, G. L. Singleton, L. J. Sepúlveda, S. Sridhar, and T. J. Webster, "Silver nanoparticle-embedded polymersome nanocarriers for the treatment of antibioticresistant infections," Nanoscale, vol. 7, no. 8, pp. 3511-3519, 2015.

[38] S. Sugumar, V. Ghosh, M. J. Nirmala, A. Mukherjee, and N. Chandrasekaran, "Ultrasonic emulsification of eucalyptus oil nanoemulsion: antibacterial activity against Staphylococcus aureus and wound healing activity in Wistar rats," Ultrasonics Sonochemistry, vol. 21, no. 3, pp. 1044-1049, 2014.

[39] K. Westesen, H. Bunjes, and M. H. J. Koch, "Physicochemical characterization of lipid nanoparticles and evaluation of their drug loading capacity and sustained release potential," Journal of Controlled Release, vol. 48, no. 2-3, pp. 223-236, 1997.

[40] G. Gainza, D. C. E. Bonafonte, B. Moreno et al., "The topical administration of rhEGF-loaded nanostructured lipid carriers (rhEGF-NLC) improves healing in a porcine full-thickness excisional wound model," Journal of Controlled Release, vol. 197, pp. 41-47, 2015.

[41] K. K. Chereddy, C.-H. Her, M. Comune et al., "PLGA nanoparticles loaded with host defense peptide LL37 promote wound healing," Journal of Controlled Release, vol. 194, pp. 138-147, 2014. 
[42] A. Bader, S. Ebert, S. Giri et al., "Skin regeneration with conical and hair follicle structure of deep second-degree scalding injuries via combined expression of the EPO receptor and beta common receptor by local subcutaneous injection of nanosized rhEPO," International Journal of Nanomedicine, vol. 7, pp. 12271237, 2012.

[43] K. Pfurtscheller, T. Petnehazy, W. Goessler, V. Bubalo, L. Kamolz, and M. Trop, "Transdermal uptake and organ distribution of silver from two different wound dressings in rats after a burn trauma," Wound Repair and Regeneration, vol. 22, no. 5, pp. 654-659, 2014.

[44] A. Meddahi-Pellé, A. Legrand, A. Marcellan, L. Louedec, D. Letourneur, and L. Leibler, "Organ repair, hemostasis, and in vivo bonding of medical devices by aqueous solutions of nanoparticles," Angewandte Chemie International Edition, vol. 53, no. 25, pp. 6369-6373, 2014.

[45] R. Sensenig, Y. Sapir, C. MacDonald, S. Cohen, and B. Polyak, "Magnetic nanoparticle-based approaches to locally target therapy and enhance tissue regeneration in vivo," Nanomedicine, vol. 7, no. 9, pp. 1425-1442, 2012.

[46] B. Brunel, G. Beaune, U. Nagarajan, S. Dufour, F. BrochardWyart, and F. M. Winnik, "Nanostickers for cells: a model study using cell-nanoparticle hybrid aggregates," Soft Matter, vol. 12, no. 38, pp. 7902-7907, 2016.

[47] J. Brandt, S. Henning, G. Michler, W. Hein, A. Bernstein, and M. Schulz, "Nanocrystalline hydroxyapatite for bone repair: an animal study," Journal of Materials Science: Materials in Medicine, vol. 21, no. 1, pp. 283-294, 2010.

[48] I. Mihatovic, M. Payer, M. Bertrams et al., "Bone tissue response to an oily calcium hydroxide suspension in tibial defects. An experimental pilot study in minipigs," Journal of CranioMaxillofacial Surgery, vol. 42, no. 7, pp. 1171-1177, 2014.

[49] A. Formhals, "Process and apparatus for preparing artificial threads," US Patent 1975504, 1934.

[50] D. Aussawasathien, C. Teerawattananon, and A. Vongachariya, "Separation of micron to sub-micron particles from water: electrospun nylon-6 nanofibrous membranes as pre-filters," Journal of Membrane Science, vol. 315, no. 1-2, pp. 11-19, 2008.

[51] M. Gorji, A. A. A. Jeddi, and A. A. Gharehaghaji, "Fabrication and characterization of polyurethane electrospun nanofiber membranes for protective clothing applications," Journal of Applied Polymer Science, vol. 125, no. 5, pp. 4135-4141, 2012.

[52] R. Rojas and N. J. Pinto, "Using electrospinning for the fabrication of rapid response gas sensors based on conducting polymer nanowires," IEEE Sensors Journal, vol. 8, no. 6, pp. 951-953, 2008.

[53] Z. Dong, S. J. Kennedy, and Y. Wu, "Electrospinning materials for energy-related applications and devices," Journal of Power Sources, vol. 196, no. 11, pp. 4886-4904, 2011.

[54] Q. P. Pham, U. Sharma, and A. G. Mikos, "Electrospinning of polymeric nanofibers for tissue engineering applications: a review," Tissue Engineering, vol. 12, no. 5, pp. 1197-1211, 2006.

[55] X. Hu, S. Liu, G. Zhou, Y. Huang, Z. Xie, and X. Jing, "Electrospinning of polymeric nanofibers for drug delivery applications," Journal of Controlled Release, vol. 185, no. 1, pp. 12-21, 2014.

[56] T. Subbiah, G. S. Bhat, R. W. Tock, S. Parameswaran, and S. S. Ramkumar, "Electrospinning of nanofibers," Journal of Applied Polymer Science, vol. 96, no. 2, pp. 557-569, 2005.

[57] P. Zahedi, I. Rezaeian, S.-O. Ranaei-Siadat, S.-H. Jafari, and P. Supaphol, "A review on wound dressings with an emphasis on electrospun nanofibrous polymeric bandages," Polymers for Advanced Technologies, vol. 21, no. 2, pp. 77-95, 2010.

[58] K. A. Rieger, N. P. Birch, and J. D. Schiffman, "Designing electrospun nanofiber mats to promote wound healing-a review," Journal of Materials Chemistry B, vol. 1, no. 36, pp. 45314541, 2013.

[59] V. Pillay, C. Dott, Y. E. Choonara et al., "A review of the effect of processing variables on the fabrication of electrospun nanofibers for drug delivery applications," Journal of Nanomaterials, vol. 2013, Article ID 789289, 22 pages, 2013.

[60] T. J. Sill and H. A. von Recum, "Electrospinning: applications in drug delivery and tissue engineering," Biomaterials, vol. 29, no. 13, pp. 1989-2006, 2008.

[61] H. S. Yoo, T. G. Kim, and T. G. Park, "Surface-functionalized electrospun nanofibers for tissue engineering and drug delivery," Advanced Drug Delivery Reviews, vol. 61, no. 12, pp. 10331042, 2009.

[62] C.-L. He, Z.-M. Huang, and X.-J. Han, "Fabrication of drugloaded electrospun aligned fibrous threads for suture applications," Journal of Biomedical Materials Research Part A, vol. 89, no. 1, pp. 80-95, 2009.

[63] T. T. T. Nguyen, C. Ghosh, S.-G. Hwang, N. Chanunpanich, and J. S. Park, "Porous core/sheath composite nanofibers fabricated by coaxial electrospinning as a potential mat for drug release system," International Journal of Pharmaceutics, vol. 439, no. 12, pp. 296-306, 2012.

[64] A. Khalf, K. Singarapu, and S. V. Madihally, "Influence of solvent characteristics in triaxial electrospun fiber formation," Reactive and Functional Polymers, vol. 90, pp. 36-46, 2015.

[65] E. A. Krogstad and K. A. Woodrow, "Manufacturing scale-up of electrospun poly(vinyl alcohol) fibers containing tenofovir for vaginal drug delivery," International Journal of Pharmaceutics, vol. 475, no. 1-2, pp. 282-291, 2014.

[66] M. Ranjbar-Mohammadi and S. H. Bahrami, "Electrospun curcumin loaded poly( $\varepsilon$-caprolactone)/gum tragacanth nanofibers for biomedical application," International Journal of Biological Macromolecules, vol. 84, pp. 448-456, 2016.

[67] M. R. Mohammadi, S. Rabbani, S. H. Bahrami, M. T. Joghataei, and F. Moayer, "Antibacterial performance and in vivo diabetic wound healing of curcumin loaded gum tragacanth/poly( $\varepsilon$ caprolactone) electrospun nanofibers," Materials Science and Engineering C, vol. 69, pp. 1183-1191, 2016.

[68] T. Zhou, N. Wang, Y. Xue et al., "Electrospun tilapia collagen nanofibers accelerating wound healing via inducing keratinocytes proliferation and differentiation," Colloids and Surfaces B: Biointerfaces, vol. 143, pp. 415-422, 2016.

[69] D. W. Song, S. H. Kim, H. H. Kim, K. H. Lee, C. S. Ki, and Y. H. Park, "Multi-biofunction of antimicrobial peptideimmobilized silk fibroin nanofiber membrane: implications for wound healing," Acta Biomaterialia, vol. 39, pp. 146-155, 2016.

[70] Z. Xie, C. B. Paras, H. Weng et al., "Dual growth factor releasing multi-functional nanofibers for wound healing," Acta Biomaterialia, vol. 9, no. 12, pp. 9351-9359, 2013.

[71] A. Haider, S. Kwak, K. C. Gupta, and I.-K. Kang, "Antibacterial activity and cytocompatibility of PLGA/CuO hybrid nanofiber scaffolds prepared by electrospinning," Journal of Nanomaterials, vol. 2015, Article ID 832762, 10 pages, 2015.

[72] T. T. Yuan, P. M. Jenkins, A. M. DiGeorge Foushee, A. R. Jockheck-Clark, and J. M. Stahl, "Electrospun chitosan/polyethylene oxide nanofibrous scaffolds with potential antibacterial wound dressing applications," Journal of Nanomaterials, vol. 2016, Article ID 6231040, 10 pages, 2016. 
[73] G. E. Wnek, M. E. Carr, D. G. Simpson, and G. L. Bowlin, "Electrospinning of nanofiber fibrinogen structures," Nano Letters, vol. 3, no. 2, pp. 213-216, 2003.

[74] S. E. Dabney, The use of electrospinning technology to produce wound dressings [Ph.D. dissertation], The University of Akron, 2002.

[75] N. Bhattarai, D. Edmondson, O. Veiseh, F. A. Matsen, and M. Zhang, "Electrospun chitosan-based nanofibers and their cellular compatibility," Biomaterials, vol. 26, no. 31, pp. 61766184, 2005.

[76] W. Zhong, Q. Liu, Y. Wu et al., "A nanofiber based artificial electronic skin with high pressure sensitivity and 3D conformability," Nanoscale, vol. 8, no. 24, pp. 12105-12112, 2016.

[77] J. Yao, C. W. M. Bastiaansen, and T. Peijs, "High strength and high modulus electrospun nanofibers," Fibers, vol. 2, no. 2, pp. 158-186, 2014.

[78] S. Chou and K. A. Woodrow, "Relationships between mechanical properties and drug release from electrospun fibers of PCL and PLGA blends," Journal of the Mechanical Behavior of Biomedical Materials, vol. 65, pp. 724-733, 2017.

[79] S.-F. Chou, D. Carson, and K. A. Woodrow, "Current strategies for sustaining drug release from electrospun nanofibers," Journal of Controlled Release, vol. 220, pp. 584-591, 2015.

[80] C. Ball, S.-F. Chou, Y. Jiang, and K. A. Woodrow, "Coaxially electrospun fiber-based microbicides facilitate broadly tunable release of maraviroc," Materials Science and Engineering C, vol. 63, pp. 117-124, 2016.

[81] S. Sahoo, L. T. Ang, J. C.-H. Goh, and S.-L. Toh, "Growth factor delivery through electrospun nanofibers in scaffolds for tissue engineering applications," Journal of Biomedical Materials Research Part A, vol. 93, no. 4, pp. 1539-1550, 2010.

[82] J. Zeng, A. Aigner, F. Czubayko, T. Kissel, J. H. Wendorff, and A. Greiner, "Poly(vinyl alcohol) nanofibers by electrospinning as a protein delivery system and the retardation of enzyme release by additional polymer coatings," Biomacromolecules, vol. 6, no. 3, pp. 1484-1488, 2005.

[83] S. Lee, G. Jin, and J.-H. Jang, "Electrospun nanofibers as versatile interfaces for efficient gene delivery," Journal of Biological Engineering, vol. 8, 30 pages, 2014.

[84] T. Ameringer, F. Ercole, K. M. Tsang et al., "Surface grafting of electrospun fibers using ATRP and RAFT for the control of biointerfacial interactions," Biointerphases, vol. 8, no. 1, 16 pages, 2013.

[85] D. Martindale, "Biodegradable scaffolds give skin cells a better road map for self-repair," Scientific American, vol. 283, pp. 34$36,2000$.

[86] J. A. Last, S. J. Liliensiek, P. F. Nealey, and C. J. Murphy, "Determining the mechanical properties of human corneal basement membranes with atomic force microscopy," Journal of Structural Biology, vol. 167, no. 1, pp. 19-24, 2009.

[87] S. J. Liliensiek, P. Nealey, and C. J. Murphy, "Characterization of endothelial basement membrane nanotopography in rhesus macaque as a guide for vessel tissue engineering." Tissue Engineering Part A, vol. 15, no. 9, pp. 2643-2651, 2009.

[88] T. Gutsmann, G. E. Fantner, J. H. Kindt, M. Venturoni, S. Danielsen, and P. K. Hansma, "Force spectroscopy of collagen fibers to investigate their mechanical properties and structural organization," Biophysical Journal, vol. 86, no. 5, pp. 3186-3193, 2004.

[89] M. J. Dalby, N. Gadegaard, R. Tare et al., "The control of human mesenchymal cell differentiation using nanoscale symmetry and disorder," Nature Materials, vol. 6, no. 12, pp. 997-1003, 2007.

[90] C. F. Natale, M. Ventre, and P. A. Netti, "Tuning the materialcytoskeleton crosstalk via nanoconfinement of focal adhesions," Biomaterials, vol. 35, no. 9, pp. 2743-2751, 2014.

[91] M. Vandrovcova, J. Hanus, M. Drabik et al., "Effect of different surface nanoroughness of titanium dioxide films on the growth of human osteoblast-like MG63 cells," Journal of Biomedical Materials Research Part A, vol. 100, no. 4, pp. 1016-1032, 2012.

[92] E. Lamers, R. van Horssen, J. te Riet et al., "The influence of nanoscale topographical cues on initial osteoblast morphology and migration," European Cells \& Materials, vol. 20, pp. 329$343,2010$.

[93] E. K. F. Yim, S. W. Pang, and K. W. Leong, "Synthetic nanostructures inducing differentiation of human mesenchymal stem cells into neuronal lineage," Experimental Cell Research, vol. 313, no. 9, pp. 1820-1829, 2007.

[94] M.-H. Kim, Y. Sawada, M. Taya, and M. Kino-oka, "Influence of surface topography on the human epithelial cell response to micropatterned substrates with convex and concave architectures," Journal of Biological Engineering, vol. 8, 9 pages, 2014.

[95] A. D. Sezer and E. Cevher, "Biopolymers as wound healing materials: challenges and new strategies," in Biomaterials Applications for Nanomedicine, R. Pignatello, Ed., 2011.

[96] T. V. L. Hima Bindu, M. Vidyavathi, K. Kavitha, T. P. Sastry, and R. V. S. Kumar, "Preparation and evaluation of chitosangelatin composite films for wound healing activity," Trends in Biomaterials and Artificial Organs, vol. 24, no. 3, pp. 122-130, 2010.

[97] A. Tanaka, T. Nagate, and H. Matsuda, "Acceleration of wound healing by gelatin film dressings with epidermal growth factor," The Journal of Veterinary Medical Science, vol. 67, no. 9, pp. 909913, 2005.

[98] B. D. Emir and M. O. Raphael, "Perspectives on: chitosan drug delivery systems based on their geometries," Journal of Bioactive and Compatible Polymers, vol. 21, no. 4, pp. 351-368, 2006.

[99] M. Fujita, M. Kinoshita, M. Ishihara et al., "Inhibition of vascular prosthetic graft infection using a photocrosslinkable chitosan hydrogel," Journal of Surgical Research, vol. 121, no. 1, pp. 135-140, 2004.

[100] M. Michela, R. Silvia, F. Franca et al., "Sponge-like dressings based on the association of chitosan and sericin for the treatment of chronic skin ulcers. I. Design of experiments assisted development," Journal of Pharmaceutical Sciences, vol. 105, no. 3, pp. 1180-1187, 2016.

[101] A. H. Doulabi, H. Mirzadeh, N. Samadi, S. Bagheri-Khoulenjani, M. Atai, and M. Imani, "Potential application of a visible light-induced photocured hydrogel film as a wound dressing material," Journal of Polymers, vol. 2015, Article ID 867928, 10 pages, 2015.

[102] C. Agalou, "How polymers can heal wounds," Advanced Science News, accessed on 2/8/2017, http://www.advancedsciencenews .com/polymers-can-heal-wounds/.

[103] B. D. Lawrence, Z. Pan, A. Liu, D. L. Kaplan, and M. I. Rosenblatt, "Human corneal limbal epithelial cell response to varying silk film geometric topography in vitro," Acta Biomaterialia, vol. 8, no. 10, pp. 3732-3743, 2012.

[104] E. S. Gil, S.-H. Park, J. Marchant, F. Omenetto, and D. L. Kaplan, "Response of human corneal fibroblasts on silk film surface patterns," Macromolecular Bioscience, vol. 10, no. 6, pp. 664-673, 2010. 
[105] N. W. Karuri, S. Liliensiek, A. I. Teixeira et al., "Bilogical length scale topography enhances cell-substratum adhesion of human corneal epithelial cells," Journal of Cell Science, vol. 117, no. 15, pp. 3153-3164, 2004.

[106] A. H. Doulabi, H. Mirzadeh, M. Imani, and N. Samadi, "Chitosan/polyethylene glycol fumarate blend film: physical and antibacterial properties," Carbohydrate Polymers, vol. 92, no. 1, pp. 48-56, 2013.

[107] A. Hashemi Doulabi, H. Mirzadeh, and M. Imani, "Miscibility study of chitosan/polyethylene glycol fumarate blends in dilute solutions," Journal of Applied Polymer Science, vol. 127, no. 5, pp. 3514-3521, 2013.

[108] S. Sharifi, H. Mirzadeh, M. Imani et al., "Synthesis, photocrosslinking characteristics, and biocompatibility evaluation of $\mathrm{N}$-vinyl pyrrolidone/polycaprolactone fumarate biomaterials using a new proton scavenger," Polymers for Advanced Technologies, vol. 19, no. 12, pp. 1828-1838, 2008.

[109] D. Li, W. Nie, L. Chen et al., "Fabrication of curcuminloaded mesoporous silica incorporated polyvinyl pyrrolidone nanofibers for rapid hemostasis and antibacterial treatment," RSC Advances, vol. 7, no. 13, pp. 7973-7982, 2017.

[110] J.-F. Pan, N.-H. Liu, H. Sun, and F. Xu, "Preparation and characterization of electrospun PLCL/ poloxamer nanofibers and dextran/gelatin hydrogels for skin tissue engineering," PLoS ONE, vol. 9, no. 11, article el12885, 2014. 

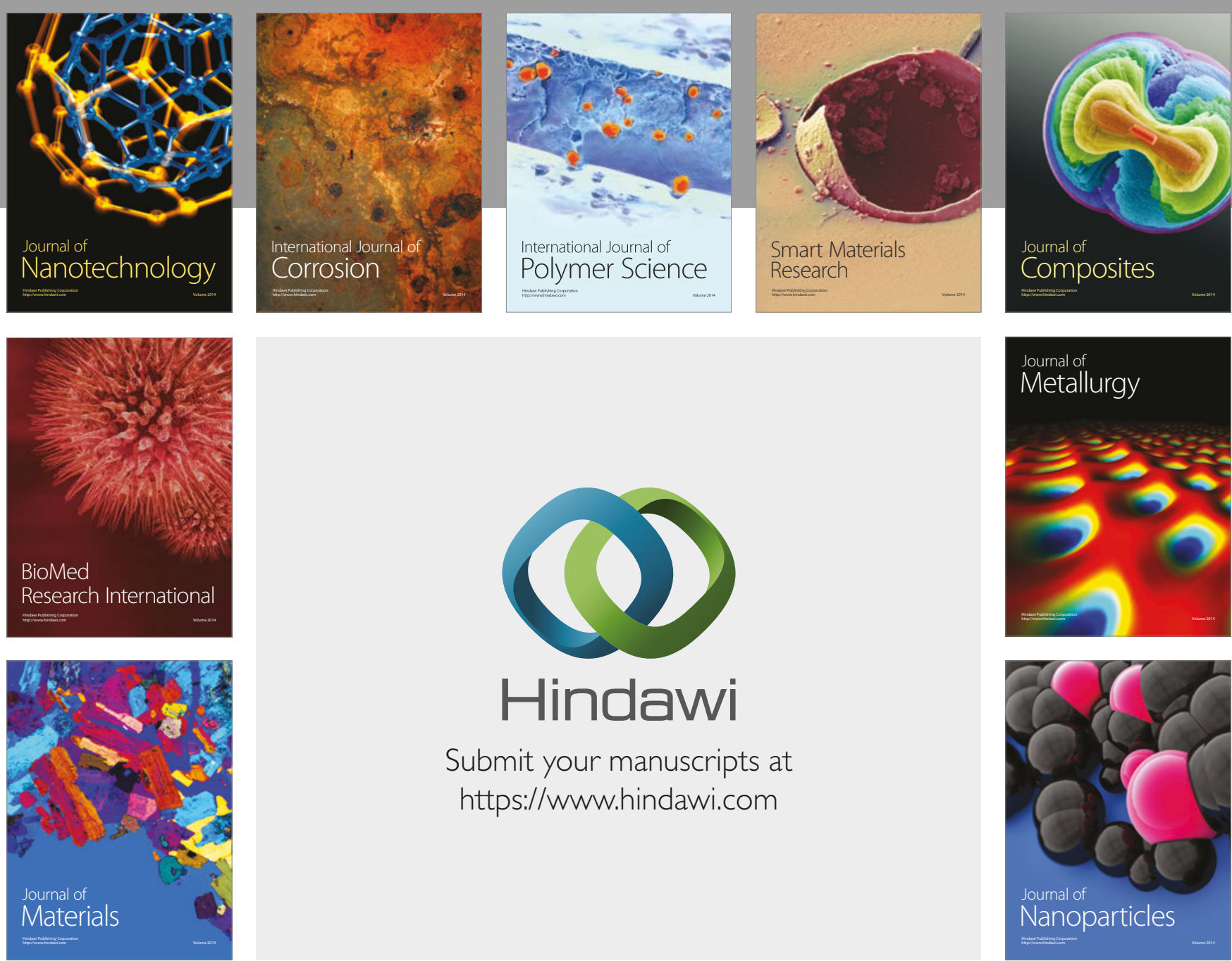

\section{Hindawi}

Submit your manuscripts at

https://www.hindawi.com
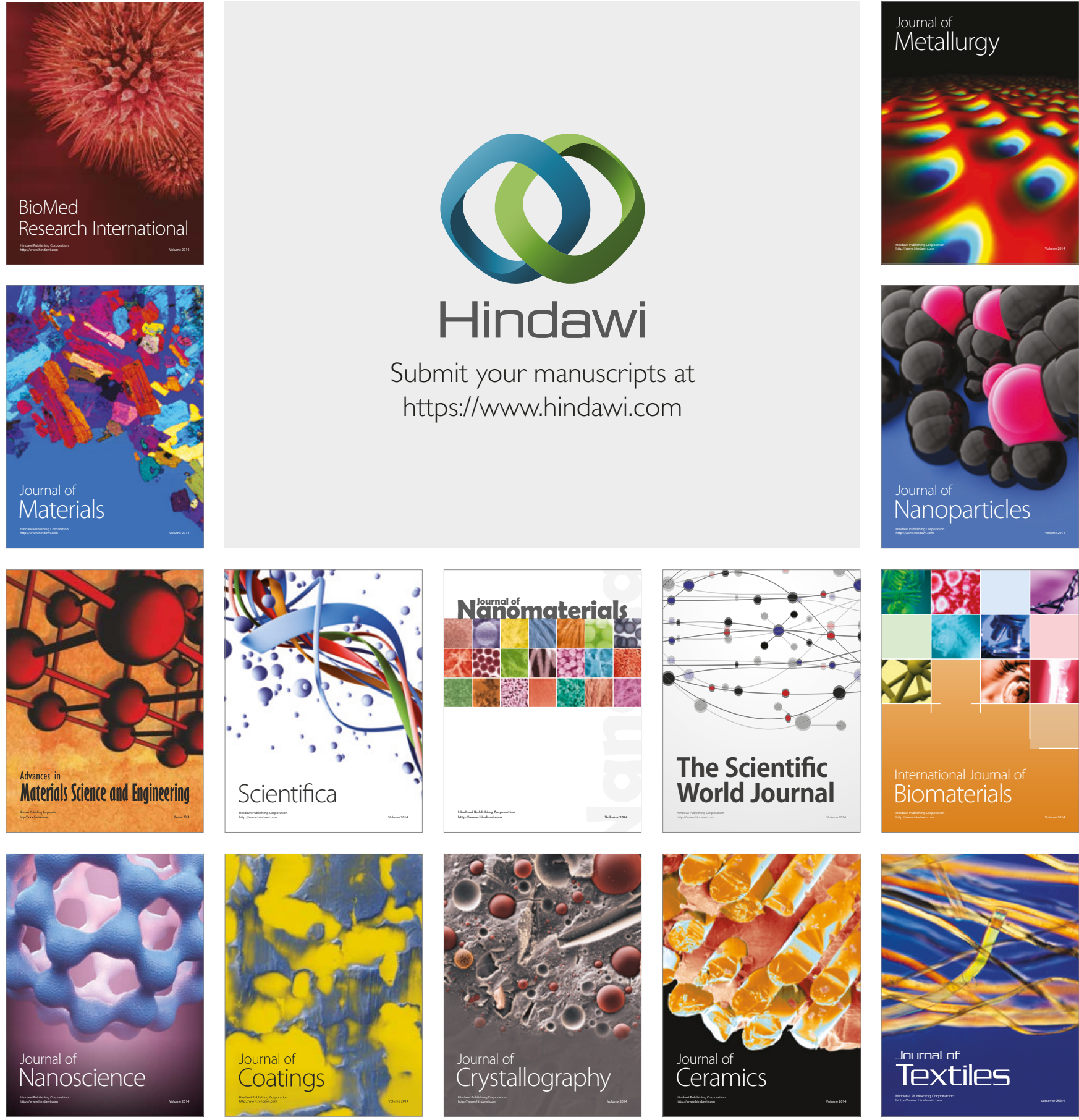

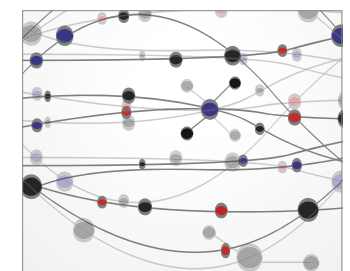

The Scientific World Journal
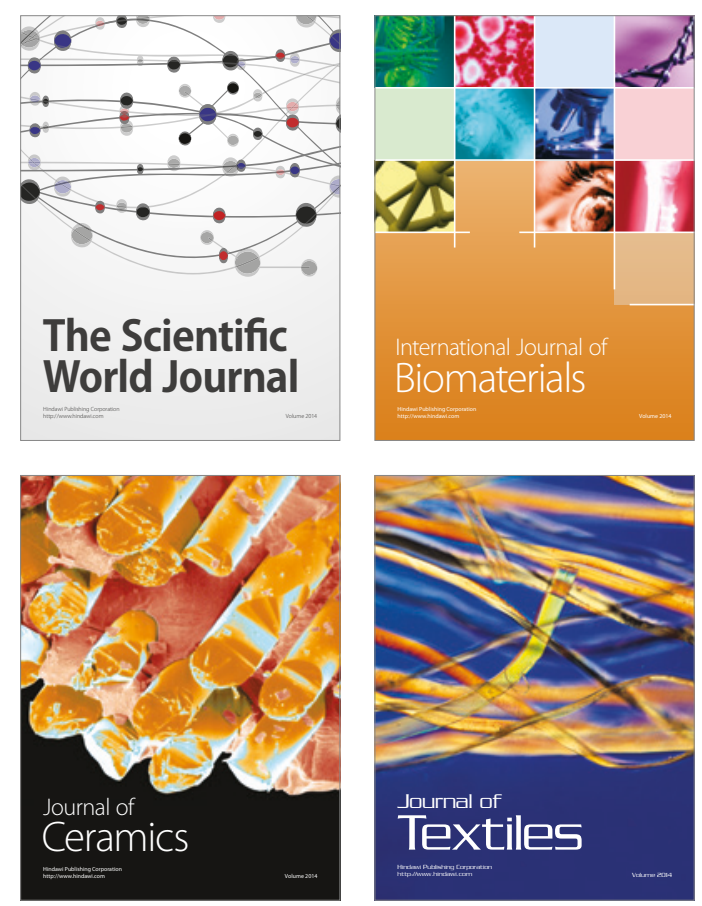